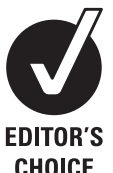

CHOICE

\title{
Firearms regulation and declining rates of male suicide in Quebec
}

\author{
Mathieu Gagné, ${ }^{1}$ Yvonne Robitaille, ${ }^{1,2}$ Denis Hamel, ${ }^{1}$ Danielle St-Laurent ${ }^{1}$
}

- Additional tables A and B are published online only. To view these files please visit the journal online (http:// injuryprevention.bmj.com).

1 Institut national de santé publique du Québec, Sainte-Foy, Quebec, Canada

${ }^{2}$ Département de médecine sociale et préventive, Université de Montréal, Montréal, Quebec, Canada

\section{Correspondence to}

Mathieu Gagné, Institut national de santé publique du Québec, 945 Wolfe Avenue, 3rd Floor, Sainte-Foy,

Quebec G1V 5B3, Canada; mathieu.gagne@inspq.qc.ca

Accepted 15 December 2009 Published Online First 29 June 2010

\section{ABSTRACT}

Objectives To examine whether significant changes in method-specific male suicide rates occurred in the province of Quebec after stronger firearms regulations were introduced in Canada in 1991; to ascertain whether more stringent firearms regulations influence firearms and total suicide trends among men and to determine whether different results are obtained according to the statistical methods used.

Study design Descriptive analyses of time trends in method-specific suicide rates for men from 1981 to 2006 using Joinpoint regression models and pre-post firearms regulation analyses.

Setting Quebec (Canada).

Patients or Subjects Men who have commited suicide aged 15-34, 35-64 and 65 years and over, based on the Quebec mortality database, 1981-2006.

Interventions $A$ national firearms control initiative enacted in 1991.

Results The Joinpoint regression models suggest that firearm suicide rates declined towards the end of the 1990s. Since 1996, the pace of decline was twice as great in men aged 15-34 years (annual percentage change (APC) $-11.1 \%$ ) compared with men aged 35-64 years (APC $-5.6 \%$ ). Total suicide rates also declined among men aged $15-34$ and 35-64 years during this period. Pre-post firearms regulation Poisson regression analyses failed to detect the specific point in time when significant changes in the trend occurred.

Conclusions Male firearm suicide rates declined following the introduction of restrictive firearms regulations in Canada. Whether this represents a causal relationship requires further study.

During the 1990s, rates of suicide among men reached an all-time high in the province of Quebec. ${ }^{1}$ Since 2000, suicide rates in Quebec have declined strikingly, particularly among teenagers and young adult men. ${ }^{2}$ Similar findings have been observed in other countries (Australia, ${ }^{3}$ New Zealand, ${ }^{4}$ Scotland ${ }^{5}$ and England), ${ }^{6}$ although in each the reasons for the decline are still unclear. In 1991, the federal government of Canada enacted new firearms control legislation and regulations (Bill C-17). These regulations were intended to enhance public safety from unintentional firearms injuries and suicides, to reduce criminal firearms use and addressed safe storage practices as well as a reinforcement of the screening process for obtaining a firearm acquisition certificate.

To prevent suicide, other interventions have been proposed, but only two seem to be efficacious, that is educating physicians to be better at recognising and treating depression, and restricting access to lethal methods. ' Firearms remain the most lethal methods of suicide. ${ }^{8}$ Decreasing the availability of firearms was thus seen as a plausible, albeit insufficient, explanation for the reduction in suicide rates in Quebec. ${ }^{2}$ Based on Quebec suicide data, this assumption has been challenged. Caron et al ${ }^{9}$ attempted to assess changes in the total suicide and firearm suicide rates before and after firearms regulations (Bill C-17) through the use of an interrupted time-series, a well-known technique for evaluating interventions. ${ }^{10}$ Their results suggested that regulation neither contributed to the downward trend in firearm suicides, nor reduced the upward trend in the total suicide rate. ${ }^{9}$ However, the period examined in their study was limited and they failed to take account of the fact that regulations are implemented gradually and compliance is not immediate.

Accordingly, the present study re-examines method-specific suicide trends to assess whether significant changes occurred during the firearms regulation implementation period and to determine whether the total suicide rate diminished. In particular, our objectives are to examine whether strengthening firearms regulations can have influenced firearm suicide trends, whether compensatory shifts to other methods occur, and to determine whether different results are obtained according to the statistical methods used.

\section{METHODS}

Mortality data for the period 1981-2006 were obtained from Quebec's death database. Because women had low firearm suicide rates, analyses were limited to men. We included all male deaths coded as suicides according to the International Classification of Diseases, 9th revision (E950-E959) for the period of 1981-99, and according to the 10th revision (X60-X84, Y87.0) for the period of 2000-6.

This study is based on 25057 deaths. Five groups of suicide methods were considered: hanging (including strangulation and suffocation); firearms (including explosives); poisoning with gases (including vehicle exhaust); poisoning by solids or liquids (including drug poisoning) and other methods (including jumping, drowning and injury from sharp objects) (see supplementary table A available online only). Analyses were stratified by age group because firearms regulations appear to be more effective in reducing suicide in the younger age group compared with other age groups. ${ }^{11}$ The age groups included 15-34, 35-64, and 65 years and older. Population data were provided by the Quebec Statistics Institute. Age-specific and age-standardised death rates per 100000 were calculated for each calendar year using direct standardisation, with 
the 2001 Quebec census population as the reference population. Five-year age groups were used for the standardisation.

\section{Main statistical analysis}

We analysed method-specific suicide trends using Joinpoint regression software version 3.3.1 (http://srab.cancer.gov/joinpoint/) to examine whether changes were consistent with the implementation of restrictive firearms regulations. The Joinpoint method has recently been used to detect changes in the direction and/or magnitude of linear trends in suicide rates. ${ }^{5} 1213$ A 'joinpoint' is any change in trend connecting two contiguous linear segments. It pinpoints changes in linear trends. Subsequent to Canada's passage of Bill C-17 in 1991, a significant change in the slope in the post-implementation period could be interpreted as reflecting the impact of the new firearms regulations. Change may correspond to incremental shifts or abrupt variations from 1 year to another, or to modifications in the average unit of change per time interval. The effect may not persist for a significant period afterwards. In this case, Joinpoint should identify another inflexion in the slope, a return to the pre-legislation trend after a period of momentary effect. The Joinpoint regression procedure involves a sequence of permutation tests performed on a Monte Carlo sample of a dataset to select a final model that includes a Bonferroni adjustment to control for error probability arising from multiple tests. ${ }^{14}$ The analysis begins with no joinpoints, and then determines whether the addition of one or more joinpoints provides a statistically significant improvement in the model.

In our analysis, we set as parameters a maximum of four joinpoints allowed to enter the final model and a minimum of 4 years between two joinpoints. To characterise the slope of the linear segment in terms of suicide rates over time, we used an estimated annual percentage change (APC) using the log of the suicide rates as the dependent variable and the year as the independent variable. Our models assumed that the random errors were heteroscedastic between rate variances for each observation. As recommended by Kim et $a l^{14}$ we repeated the analysis using several values of the autocorrelation parameter; the results were similar with all values of the autocorrelation parameter up to 0.6.

\section{Alternative statistical analysis}

To illustrate the effect of the period examined and expected time effect of intervention parameters, we used pre-post firearms regulation Poisson regression analysis to compare change in the trend of suicide rates before and after the introduction of Bill C17. A change in intercept between the before and after-the-law segments indicates a step change, whereas a change in slope indicates a trend change. Negative binomial regressions were used when there was evidence of overdispersion.

For the Poisson regression, we fitted three models. Model A was used to estimate the change in trend in suicide rates before and after enactment of the law in 1992, with analyses restrained to 1987-2001. Model B was the same but used all the data available, that is from 1981 to 2006. Model C was used to estimate the change in trend when the time effect of the intervention was shifted to 1995 and all the data available were used. For a particular method of suicide, the model is expressed as:

$$
\begin{aligned}
\log (\text { deaths } / \text { population })= & \alpha+\beta_{1} \times \text { Time }+\beta_{2} \times \text { Law } \\
& +\beta_{3} \times \text { Time } * \text { Law }
\end{aligned}
$$

where Law is a dummy variable coded 0 before and 1 after the expected time effect of the intervention and $\beta_{3} \times$ Time * Law is an interaction term.

The estimated APC in rate was derived as follows:

$\mathrm{APC}=\left(e^{\beta \mathrm{i}}-1\right) * 100 \%$

\section{RESULTS}

Suicide rates among men in Quebec increased significantly throughout the first two decades of the study period, reaching an all-time high at the end of the 1990s. Subsequently, they began to decline (figure 1). Figure 2 shows the evolution of method-specific suicide rates for the period 1981-2006. Over this period, among men hanging increased, replacing firearms as the main method of suicide.

Our Joinpoint analysis identified two distinct trends in firearm suicide mortality rates both in men aged 15-34 and
Figure 1 Trends in age-specific suicide rates among men, Quebec, 1981-2006. ${ }^{*}$

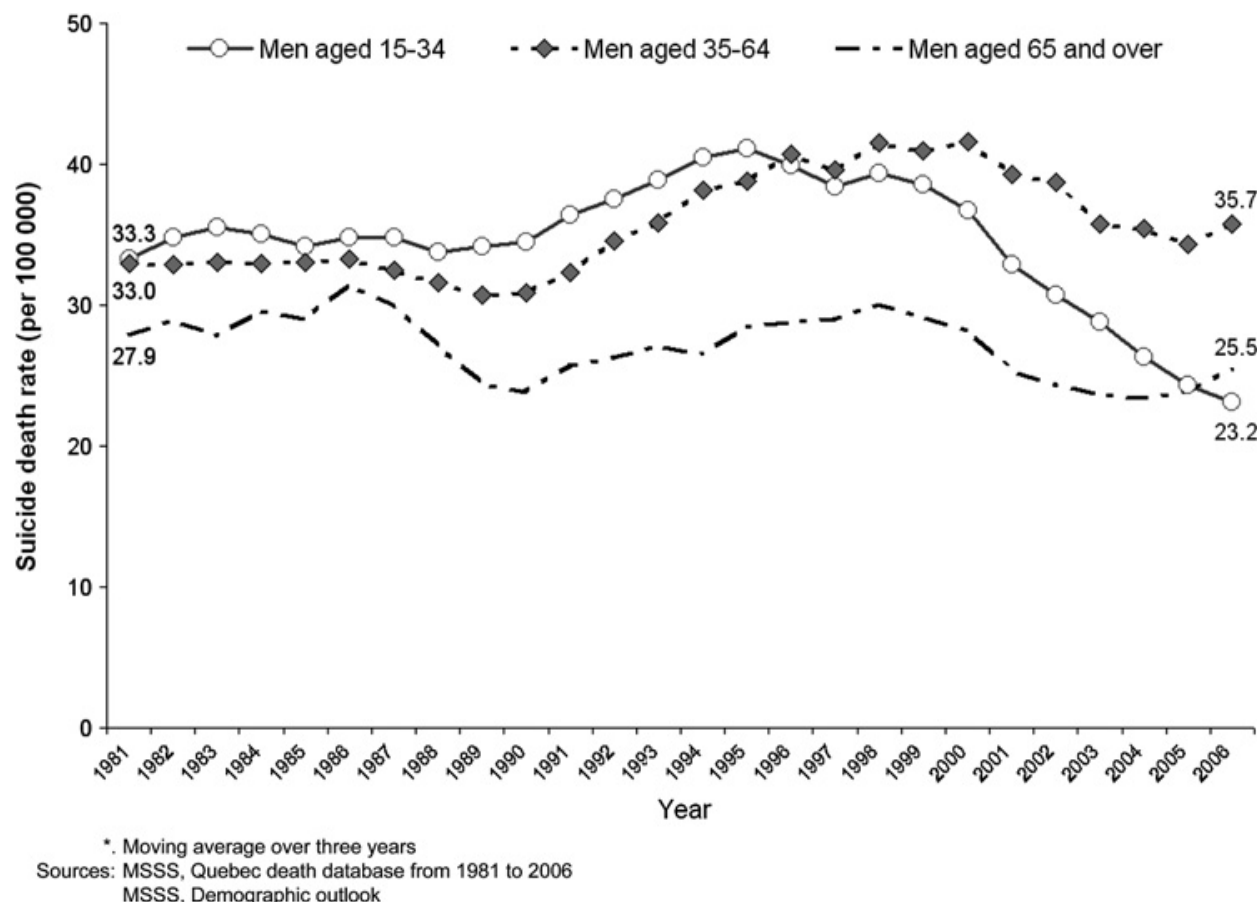


Figure 2 Trend in methods of suicide adjusted rates* among men, Quebec, 1981-2006.†
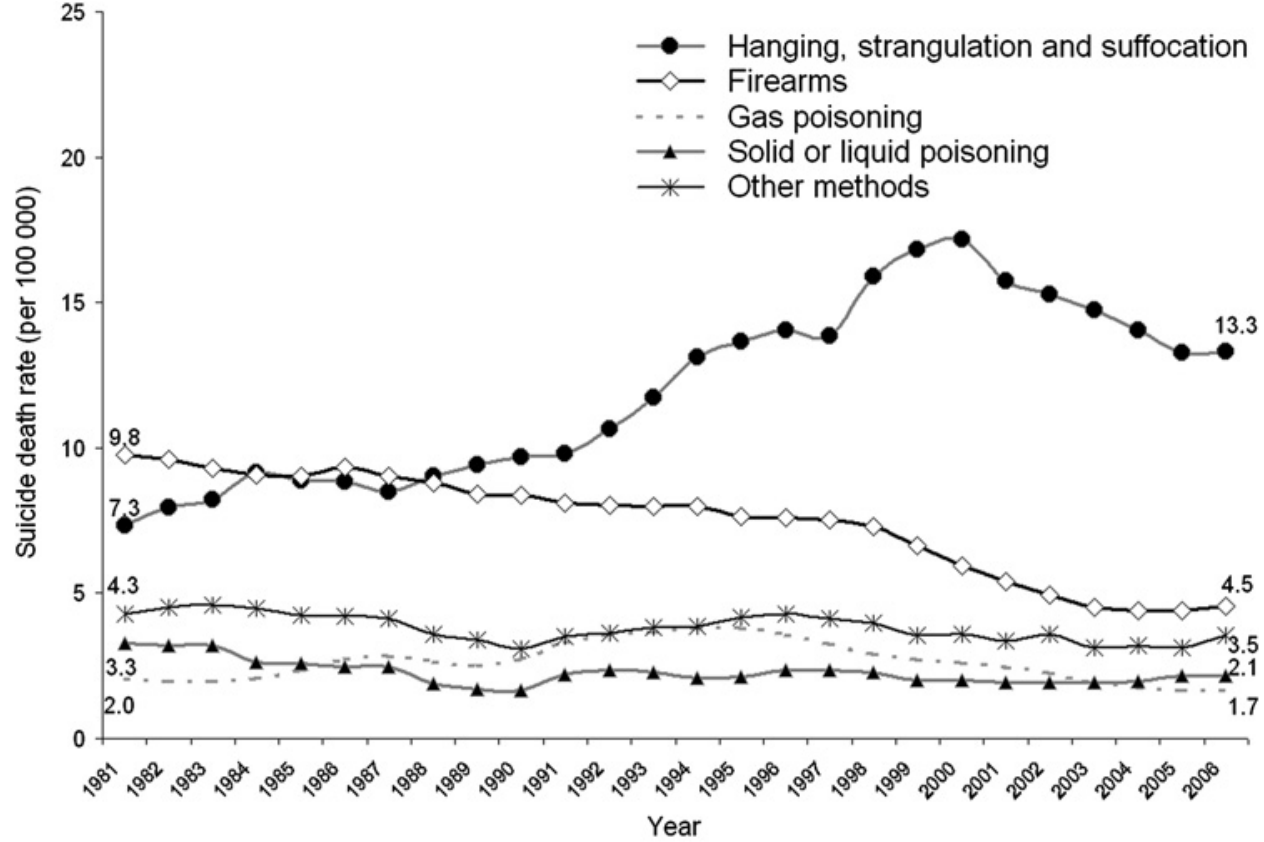

* Adjusted rates, Quebec population in 2001

t. Moving average over three years

Sources: MSSS, Quebec death database from 1981 to 2006 MSSS, Demographic outlook
35-64 years (table 1). In young men, the rate decreased moderately between 1981 and 1996 (APC -2.7\%) and then declined far more after 1996 (APC -11.1\%). In men aged 35-64 years, the trends showed a similar less pronounced picture (APC $-1.2 \%$ for the segment 1981-97 and $-5.6 \%$ for the segment 1997-2006). Rates for hanging and gas poisoning increased until the late 1990s in the 15-34 and 35-64 years age groups, and subsequently decreased. Both declines were more substantial among young men. Among men aged 65 years and over no significant change was noticed.

The results of the pre-post firearms regulation Poisson regression analyses are summarised in supplementary table $\mathrm{B}$ (available online only) and illustrated in figure $3 \mathrm{~A}-\mathrm{C}$. There is no convincing evidence suggesting that suicide trends before the law was enacted differed from trends after enactment when the timeframe is limited to 1987-2001 (figure 3A). Changes appear, however, when the timeframe is extended to 1981-2006 (figure $3 \mathrm{~B}$ ), and are even greater when the anticipated time effect of the intervention is moved to 1995.

\section{DISCUSSION}

In Quebec, after the implementation of strengthened firearms control regulations in 1991, firearm and total suicide rates decreased significantly. The pace of the decrease was twice as high in men aged 15-34 years compared with men aged 35-64 years, whereas no change was found for men aged 65 years and older. Reductions were also observed in other methods of suicide in the late 1990s, specifically hanging and gas poisoning. Joinpoint analysis can identify the specific time when the change occurs, whereas pre-post firearms regulation Poisson regression analysis could miss this specific point in time within an overall trend.

We sought to determine whether these reductions in suicides were due mainly to the introduction of the new regulations. Caron et $a l^{9}$ concluded that the enactment of Bill C-17 in 1991 did not contribute to a decrease in the total suicide rate, nor had a significant impact on suicide by firearms. However, our findings based on a different statistical approach do not support these conclusions.
Our study differs in three main aspects. First, the earlier research was conducted over too short a period (figure $3 \mathrm{~A}$ ). Adding 10 years to the data gives more time for changes to occur (figure 3B). Second, regulations were phased in from 1992 to 1994. ${ }^{15}$ Because legislation is implemented gradually, we should not expect an abrupt change in trends immediately following the enactment of a law. Moving the time effect of the intervention from 1992 to 1995 (figure 3B and figure 3C) more accurately reflects the possible effect of the intervention, particularly on the total suicide rate. Third, we assume there is a delay between implementation of the law and behavioural changes, that is, changes in access to firearms in the home after they were required to be stored unloaded and locked. Evidence suggests that compliance was moderate among Quebec firearm owners several years after the regulations came into force, ${ }^{16}$ and this would delay detection of the effect. A re-analysis of the Quebec data using a pre-post comparison design hid the specific point in time at which the effect could be pinpointed in the trend data (figure $3 \mathrm{~A}-\mathrm{C}$ ), whereas Joinpoint analysis can identify the specific time when the change occurs (figure $3 \mathrm{D}$ ).

\section{Firearms legislation: a necessary and sufficient condition to explain the decline?}

Would suicide rates have changed without the introduction of restrictive firearms regulations? Strong associations have been found between firearms availability and suicide rates, ${ }^{17-19}$ and studies from various countries suggest that reducing access to firearms reduces firearm suicides ${ }^{20-22}$ and total suicide rates. ${ }^{23}$ The same is true for interventions aimed at other suicide methods, notably the detoxification of domestic gas ${ }^{24}$ and regulations restricting paracetamol pack size. ${ }^{25}$

In this study, the APC in the firearm suicide rate varied according to the age group. The presence of a firearm in the home is a risk factor for youth suicide, ${ }^{26}$ and even more so when household firearms are accessible and loaded. ${ }^{27}$ Previous research suggests that more restrictive firearms regulations might be expected to be more efficacious in reducing suicide in the 
Table 1 Joinpoint analyses for total suicide rates and rates for specific methods among men by age group, Quebec, 1981-2006

\begin{tabular}{|c|c|c|c|c|}
\hline & Joinpoint (years) & Segment & $\mathrm{APC} \dagger$ & $95 \% \mathrm{Cl}$ \\
\hline \multicolumn{5}{|l|}{ Men aged $15-34$ years } \\
\hline \multirow[t]{2}{*}{ All methods: total rate } & & 1981-1999 & $1.1^{*}$ & (0.5 to 1.7$)$ \\
\hline & 1999 & 1999-2006 & $-8.4^{*}$ & $(-11.0$ to -5.7$)$ \\
\hline \multirow[t]{2}{*}{ Hanging } & & 1981-1999 & $5.5^{*}$ & (4.5 to 6.4 ) \\
\hline & 1999 & 1999-2006 & $-7.1^{*}$ & $(-10.4$ to -3.6$)$ \\
\hline \multirow[t]{2}{*}{ Firearms } & & $1981-1996$ & $-2.7^{*}$ & $(-4.1$ to -1.3$)$ \\
\hline & 1996 & 1996-2006 & $-11.1^{*}$ & $(-14.8$ to -7.2$)$ \\
\hline \multirow[t]{2}{*}{ Gas poisoning } & & 1981-1995 & $4.6^{*}$ & (1.9 to 7.3 ) \\
\hline & 1995 & 1995-2006 & $-13.0^{*}$ & $(-17.3$ to -8.4$)$ \\
\hline Solid or liquid poisoning & & 1981-2006 & $-5.2^{*}$ & $(-6.5$ to -4.0$)$ \\
\hline Other methods & & 1981-2006 & -1.0 & $(-2.1$ to 0.2$)$ \\
\hline \multicolumn{5}{|l|}{ Men aged $35-64$ years } \\
\hline \multirow[t]{3}{*}{ All methods: total rate } & & 1981-1999 & -0.8 & $(-3.1$ to 1.4$)$ \\
\hline & 1989 & 1989-1999 & $3.2^{*}$ & (1.5 to 4.9$)$ \\
\hline & 1999 & 1999-2006 & $-3.5^{*}$ & $(-5.6$ to -1.4$)$ \\
\hline \multirow[t]{3}{*}{ Hanging } & & $1981-1991$ & 1.0 & $(-1.6$ to 3.8$)$ \\
\hline & 1991 & 1991-1999 & $10.4^{*}$ & (6.7 to 14.1$)$ \\
\hline & 1999 & 1999-2006 & $-3.9 *$ & $(-6.5$ to -1.3$)$ \\
\hline \multirow[t]{2}{*}{ Firearms } & & $1981-1997$ & $-1.2^{*}$ & $(-2.0$ to -0.4$)$ \\
\hline & 1997 & 1997-2006 & $-5.6^{*}$ & $(-7.6$ to -3.6$)$ \\
\hline \multirow[t]{2}{*}{ Gas poisoning } & & 1981-1995 & $6.0^{*}$ & (3.7 to 8.4$)$ \\
\hline & 1995 & 1995-2006 & $-6.3^{*}$ & $(-8.8$ to -3.7$)$ \\
\hline Solid or liquid poisoning & & $1981-2006$ & -0.8 & $(-1.9$ to 0.3$)$ \\
\hline Other methods & & $1981-2006$ & -0.5 & $(-1.4$ to 0.3$)$ \\
\hline \multicolumn{5}{|l|}{ Men aged 65 years and over } \\
\hline All methods: total rate & & $1981-2006$ & -0.6 & $(-1.3$ to 0.1$)$ \\
\hline Hanging & & $1981-2006$ & 0.2 & $(-0.9$ to 1.4$)$ \\
\hline Firearms & & $1981-2006$ & -1.0 & $(-2.0$ to 0.1$)$ \\
\hline Gas poisoning $\ddagger$ & & $1981-2006$ & - & - \\
\hline Solid or liquid poisoning $\neq$ & & $1981-2006$ & - & - \\
\hline Other methods & & $1981-2006$ & $-2.8^{*}$ & $(-3.9$ to -1.7$)$ \\
\hline \multicolumn{5}{|l|}{ Men: all ages§ } \\
\hline \multirow[t]{2}{*}{ All methods: total rate } & & 1981-1999 & $1.3^{*}$ & (0.7 to 1.9$)$ \\
\hline & 1999 & $1999-2006$ & $-4.2^{*}$ & $(-6.3$ to -2.0$)$ \\
\hline \multirow[t]{2}{*}{ Hanging } & & $1981-1999$ & $5.0^{*}$ & $(4.2$ to 5.8$)$ \\
\hline & 1999 & $1999-2006$ & $-3.2^{*}$ & $(-5.7$ to -0.7$)$ \\
\hline \multirow[t]{2}{*}{ Firearms } & & 1981-1997 & $-1.7^{*}$ & $(-2.3$ to -1.1$)$ \\
\hline & 1997 & 1997-2006 & $-6.8^{*}$ & $(-8.3$ to -5.2$)$ \\
\hline \multirow[t]{2}{*}{ Gas poisoning } & & $1981-1995$ & $5.4^{*}$ & (3.7 to 7.1$)$ \\
\hline & 1995 & 1995-2006 & $-8.1^{*}$ & $(-10.2$ to -6.0$)$ \\
\hline Solid or liquid poisoning & & $1981-2006$ & $-1.5^{*}$ & $(-2.5$ to -0.5$)$ \\
\hline Other methods & & $1981-2006$ & $-1.0^{*}$ & $(-1.8$ to -0.2$)$ \\
\hline
\end{tabular}

Sources: MSSS, Quebec death database from 1981 to 2006.

MSSS, demographic outlook.

${ }^{*}$ Annual percentage change (APC) is statistically significantly different from zero (two-sided $p<0.05$, calculated using a $t$ test)

†APC, that is, the slope of the line segment.

$\ddagger$ Dropped from the analysis because the log-linear model does not deal with a rate equal at zero.

$\S$ Age-adjusted rates, Quebec population in 2001

younger age group compared with other age groups. ${ }^{11}$ Suicide attempts by young people are probably more impulsive and are thus presumably strongly affected by method availability. ${ }^{18}$ Conversely, the less significant decline in firearm suicides among older men (35-64 and 65 years and over) may be due to the fact that men in these age groups are more likely to own a securely stored firearm. In youth suicide attempts, most firearms involved originate from the individual's home and are generally owned by a household member. ${ }^{28}$

We cannot firmly conclude that the decline in the firearm suicide rate in Quebec would not have occurred without the introduction of Bill C-17. Firearm suicide rates have been decreasing among young men in Scotland, ${ }^{5}$ and the total firearm suicide rate in the USA fell by $1.1 \%$ annually between 1999 and
$2005^{29}$ without any new gun control laws. On the other hand, neither Scotland nor the USA reported any change in trend like that observed in Quebec, but rather a monotonic decrease.

Is legislation alone powerful enough to produce a significant change in trend in the desired direction? Suicides commonly occur during an acute short-term mental health crisis. ${ }^{30}$ According to the 'availability hypothesis', if a method is not available during the crisis, an alternative choice could be less lethal because it involves more planning, or allows time for the suicidal impulse to subside. ${ }^{31}$ Restricting access to lethal methods of suicide does not address an individual's psychological distress, however, and to achieve maximum prevention, access restrictions should be complemented by other interventions, such as depression recognition and treatment by physicians. 
a

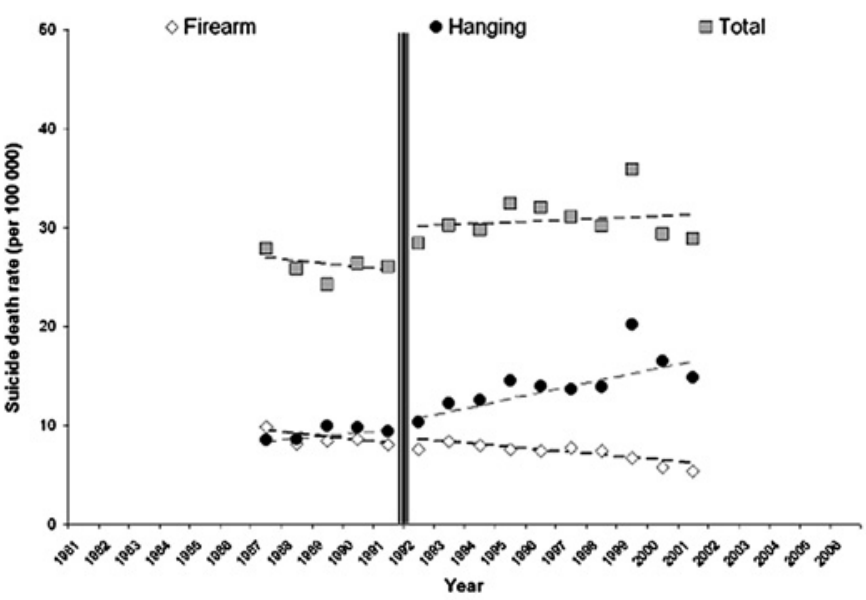

C

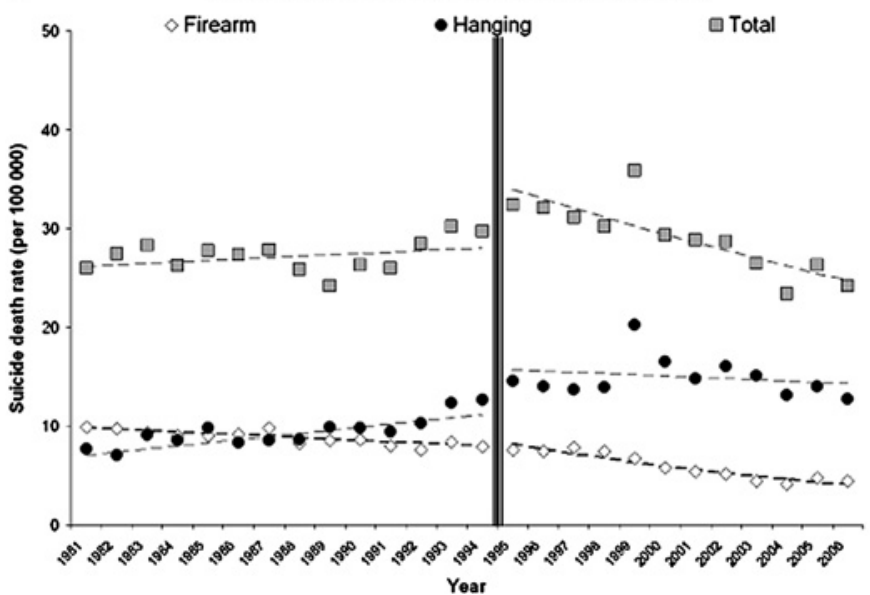

b

1981-2006, effect of intervention in 1992

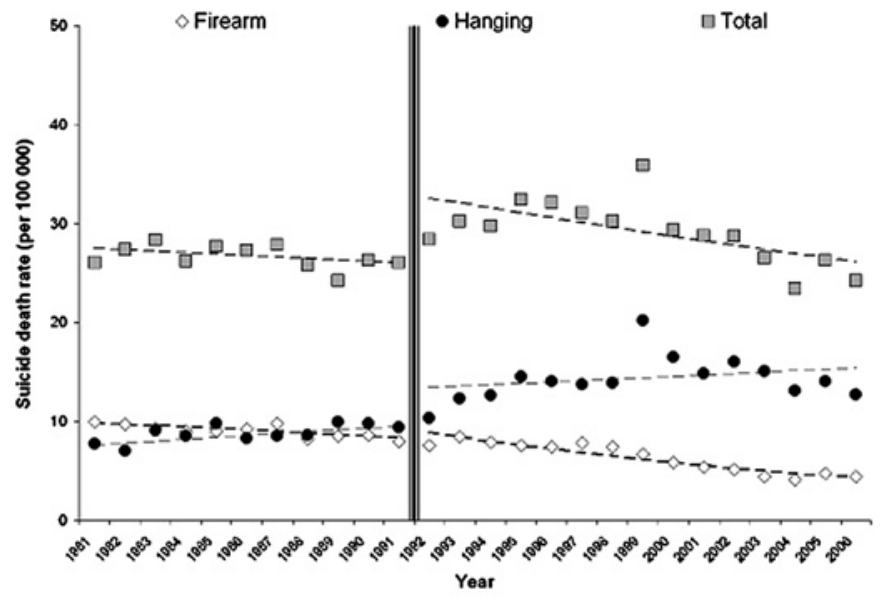

d 1981-2006, Joinpoint analysis, no fixed time on intervention

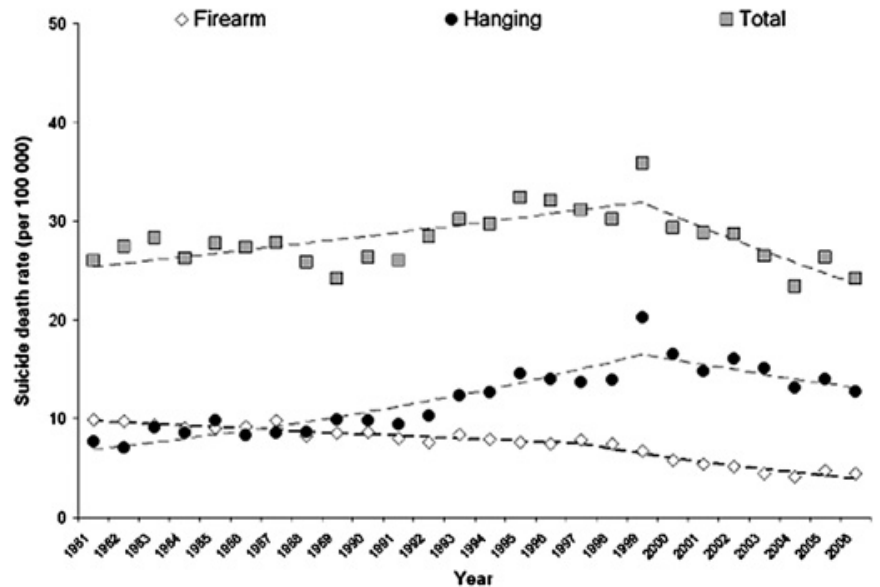

Figure 3 Suicide rates by firearms, hanging and total suicide rates among men, Quebec, 1981-2006, according to methodological choices.

Rates have declined for other methods of suicide, particularly hanging and gas poisoning. Other factors probably contributed to the downward trend in suicides by these methods as well as firearm suicide. In Australia, the decrease in young male suicide rates was associated with a national suicide prevention strategy. $^{3}$ The decline of suicide by hanging coincides with a period in which Quebec was developing a national suicide prevention strategy. The strategy mainly focused on men, especially younger men, who have experienced the largest decline. Interestingly, the decrease in firearm suicide rates preceded the launch of the national suicide prevention strategy for Quebec. In respect to gas poisoning suicide, the introduction of new technology to reduce the toxicity of emissions from car internal combustion engines could be a possible explanation for the reduction, as in Scotland. ${ }^{32}$ To complicate matters, unemployment rates diminished over the same period after economic turbulence in the early 1990s, as did methods for managing mental health problems and probably impacted suicide trends.

Many authors have also observed an increase in suicide by hanging in the last two decades of the 20th century. ${ }^{29} 33-36$ Some authors have noted the possibility of substitution or displacement after the introduction of restrictive firearms regulations. ${ }^{9} 33 \quad 34$ The reasons are unknown, but greater acceptability of hanging compared with death by firearms was proposed to explain the modification in method preferences, especially by young men. ${ }^{34}$ In Britain, changes in method pref- erences have been suggested as a possible explanation for the increased choice of hanging as a suicide method. This may be related to growing public acceptance as the stigma surrounding hanging waned following its abolition as a form of capital punishment. ${ }^{37}$ Alternatively, firearm massacres like that which occurred at Polytechnique engineering school in Montréal 20 years ago may have stigmatised firearms and thus contributed to the decline in firearm suicides. Subsequently, the Canadian government introduced Bill C-17 in 1991 and a new Firearms Act in 1995, Bill C-68, which included new weapons restrictions and required the licensing of all firearms by 2001 and registration of all firearms by 2003. Considering the gradual introduction and implementation of the legislation enacted at the end of 1995, it is not reasonable to anticipate any immediate changes in trend.

\section{Strengths and weaknesses of the study}

In our study, using 26 years of routinely collected data, Joinpoint regression analyses were conducted to identify the timing of significant changes in male firearm suicide rates in Quebec. These changes were related to the implementation of more restrictive firearms regulations. The advantage of the Joinpoint method is that it can model changes over time and identify the time point when such changes occur.

Nevertheless, our study has limitations. The study period covered two cause-of-death classifications. In 2000 the 9th 


\section{What is already known on this subject}

Restricting access to a lethal method, such as firearms, decreases suicide by that method.

\section{What this study adds}

The downward trend in firearm suicide rates among men has significantly accelerated several years after Canada enacted a firearms control initiative (Bill C-17) particularly among young men.

- This downward trend has not resulted in compensatory shifts to other methods.

- We conclude that this decline might be causally related to these regulations.

- When an intervention's effect is delayed, a joinpoint analysis may be more appropriate than a pre-post comparison study as the latter cannot account for lagged effects.

revision of the ICD was replaced by the 10th, but this change does not seem to have had any effect on the number of deaths classified as suicide. ${ }^{38}$ In Australia, it has been suggested that suicides may be under-enumerated in recent death data, ${ }^{39}$ but we found no indication of this because the Quebec death database is completed by records of deaths investigated by the Coroner's office. Furthermore, we described trends at a basic level. The contribution of various well-known risk factors for suicide-unemployment, prescription of antidepressants, divorce-could not be included in a more complex model due to Joinpoint regression limits. Finally, statistics for the year 1999 were skewed by an increase in suicides immediately following the media coverage of the death by hanging in Quebec City of a popular television reporter, ${ }^{40}$ and may have had an impact on our results. An analysis of routinely collected data is often not sufficient to judge the efficacy of an intervention. Canada's restrictive federal firearms regulations were implemented gradually, leaving time during this natural experiment for a number of other changes supplying plausible alternative interpretations to occur.

\section{CONCLUSIONS}

Firearm suicide rates declined significantly towards the end of the 1990s following the introduction of more restrictive firearms legislation in Canada. The decline was noted once the legislation had been well established. The downward trend in firearm suicide rates cannot be solely attributed to the 1991 legislation. However, the decline was marked among young men, and evidence suggests that restricting access to firearms in this age group might be effective in reducing suicides. Furthermore, a reduction in the rates of firearm-related suicides was not associated with compensatory shifts to other methods. With the information available, it is reasonable to conclude that the decline in the firearm suicide rate might well reflect the introduction of restrictive firearms regulations. In any case, the impact of firearms regulations in Quebec cannot be ruled out.

Acknowledgements The authors would like to thank Dr B Pless (McGill University) for help and advice with this manuscript.

\section{Competing interests None.}

Provenance and peer review Not commissioned; externally peer reviewed.

\section{REFERENCES}

1. St Laurent D, Bouchard C. L'épidémiologie du suicide au Québec:que savons-nous de la situation récente? Québec: INSPQ, 2004.

2. Gagné M, St Laurent D. Évolution du suicide au Québec. Frontières 2008;21:44-52.

3. Morrell S, Page AN, Taylor RJ. The decline in Australian young male suicide. Soc Sci Med 2007;:643:747-54

4. Ministry of Health. New Zealand suicide trends: mortality 1921-2003, hospitalisations for intentional self-harm 1978-2004. Wellington: Ministry of Health, 2006.

5. Stark C, Stockton D, Henderson R. Reduction in young male suicide rates in Scotland. BMC Public Health 2008;8:80.

6. Biddle L, Brock A, Brookes ST, et al. Suicide rates in young men in England and Wales in the 21st century: time trend study. BMJ 2008;336:539-42.

7. Mann JJ, Apter A, Bertolote J, et al. Suicide prevention strategies: a systematic review. JAMA 2005;294:2064-74.

8. Elnour AA, Harrison J. Lethality of suicide methods. Inj Prev 2008;14:39-45.

9. Caron J, Julien M, Huang JH. Changes in suicide methods in Quebec between 1987 and 2000: the possible impact of bill C-17 requiring safe storage of firearms. Suicide Life Threat Behav 2008;38:195-208.

10. Cook TD, Campbel DT. Quasi-experiments: interrupted time-series designs. In: Quasi-experimentation: design and analysis issues for field settings. Chicago: Rand McNally College, 1979:207-31.

11. Sloan JH, Rivara FP, Reay DT, et al. Firearm regulations and rates of suicide. A comparison of two metropolitan areas. N Engl J Med 1990;322:369-73.

12. Chang SS, Gunnell D, Sterne JA, et al. Was the economic crisis of 1997-1998 responsible for rising suicide rates in East/Southeast Asia? A time-trend analysis for Japan, Hong Kong, South Korea, Taiwan, Singapore and Thailand. Soc Sci Med 2009;68:1322-31.

13. Tamosiunas A, Reklaitiene R, Virviciute D, et al. Trends in suicide in a Lithuanian urban population over the period 1984-2003. BMC Public Health 2006;6:184

14. Kim HJ, Fay MP, Feuer EJ, et al. Permutation tests for joinpoint regression with applications to cancer rates. Stat Med 2000;193:335-51.

15. Department of Justice Canada. C-17 - Implementation evaluation. Evaluation division policy. Ottawa: Department of Justice Canada, 1998.

16. Lavoie M, Cardinal L, Chapdelaine A, et al. The storage of household long guns: the situation in Quebec. Chronic Dis Can 2001;221:24-9.

17. Ajdacic-Gross V, Killias M, Hepp U, et al. Changing times: a longitudinal analysis of international firearm suicide data. Am J Public Health 2006;96:1752-5.

18. Miller M, Azrael D, Hepburn L, et al. The association between changes in household firearm ownership and rates of suicide in the United States, 1981-2002. Inj Prev 2006;12:178-82.

19. Miller M, Lippmann SJ, Azrael D, et al. Household firearm ownership and rates of suicide across the 50 United States. J Trauma 2007;62:1029-34.

20. Beautrais AL, Fergusson DM, Horwood LJ. Firearms legislation and reductions in firearm-related suicide deaths in New Zealand. Aust N Z J Psychiatry 2006;40:253-9.

21. Bridges FS. Gun control law Bill C-17, suicide, and homicide in Canada. Psychol Rep 2004;94:819-26.

22. Kapusta ND, Etzersdorfer E, Krall C, et al. Firearm legislation reform in the European Union: impact on firearm availability, firearm suicide and homicide rates in Austria. Br J Psychiatry 2007;19:253-7.

23. Chapman S, Alpers P, Agho K, et al. Australia's 1996 gun law reforms: faster falls in firearm deaths, firearm suicides, and a decade without mass shootings. Inj Prev 2006;12:365-72.

24. Kreitman N. The coal gas story. United Kingdom suicide rates, 1960-71. Br J Prev Soc Med 1976;30:86-93.

25. Morgan $\mathbf{O W}$, Griffiths $\mathrm{C}$, Majeed A. Interrupted time-series analysis of regulations to reduce paracetamol acetaminophen poisoning. PLoS Med 2007:44:e105.

26. Brent DA, Perper JA, Allman CJ, et al. The presence and accessibility of firearms in the homes of adolescent suicides. A case-control study. JAMA 1991;266:2989-95.

27. Grossman DC, Mueller BA, Riedy C, et al. Gun storage practices and risk of youth suicide and unintentional firearm injuries. JAMA 2005;293:707-14.

28. Grossman DC, Reay DT, Baker SA. Self-inflicted and unintentional firearm injuries among children and adolescents: the source of the firearm. Arch Pediatr Adolesc Med 1999;153:875-8.

29. Hu G, Wilcox HC, Wissow L, et al. Mid-life suicide: an increasing problem in U.S. whites, 1999-2005. Am J Prev Med 2008;35:589-93.

30. Miller M, Hemenway D. Guns and suicide in the United States. N Engl J Med 2008:359:989-91.

31. Marzuk PM, Leon AC, Tardiff K, et al. The effect of access to lethal methods of injury on suicide rates. Arch Gen Psychiatry 1992;49:451-8.

32. Skilling GD, Sclare PD, Watt SJ, et al. The effect of catalytic converter legislation on suicide rates in Grampian and Scotland 1980-2003. Scott Med J 2008;53:3-6.

33. De Leo D, Dwyer J, Firman D, et al. Trends in hanging and firearm suicide rates in Australia: substitution of method? Suicide Life Threat Behav 2003;33:151-64.

34. Klieve H, Barnes M, De Leo D. Controlling firearms use in Australia: has the 1996 gun law reform produced the decrease in rates of suicide with this method? Soc Psychiatry Psychiatr Epidemiol 2009;44:285-92. 
35. Langley J, Nada-Raja S, Alsop J. Changes in methods of male youth suicide: 1980-95. NZ Med J 2000;113:264-5.

36. Stark C, Hopkins P, Gibbs D, et al. Trends in suicide in Scotland 1981-1999: age, method and geography. BMC Public Health 2004;4:49.

37. Pounder DJ. Why are the British hanging themselves? Am J Forensic Med Pathol 1993:142:135-40.
38. Statistics Canada. Comparability of ICD-10 and ICD-9 for Mortality Statistics in Canada. Ottawa: Statistics Canada, 2005.

39. De Leo D. Suicide mortality data need revision. Med J Aust 2007;186:157-8.

40. Tousignant M, Mishara BL, Caillaud A, et al. The impact of media coverage of the suicide of a well-known Quebec reporter: the case of Gaetan Girouard. Soc Sci Med 2005:60:1919-26.

\section{Lacunae}

\section{EMAIL ERROR ENDS UP ON ROAD SIGN}

All official road signs in Wales are bilingual, so Swansea Council emailed its in-house translation service for the Welsh version of: 'No entry for heavy goods vehicles. Residential site only'. The reply duly came back and officials set the wheels in motion to create the large sign in both languages. The notice went up and all seemed well-until Welsh speakers began pointing out the embarrassing error. The English was clear enough to lorry drivers-but the Welsh read 'I am not in the office at the moment. Send any work to be translated'. The blunder was not the only time Welsh has been translated incorrectly or put in the wrong place:

- Cyclists between Cardiff and Penarth in 2006 were left confused by a bilingual road sign telling them they had problems with an 'inflamed bladder'.

- In the same year, a sign for pedestrians in Cardiff reading 'Look Right', in English read 'Look Left' in Welsh.

[From the BBC News website. Contributed by Mike Hayes]

Injury Prevention 2010;16:253. doi:10.1136/ip.2010.028456 